„Przekłady Literatur Słowiańskich”. T. 11, cz. 1, s. 1-15

ISSN 2353-9763 (wersja elektroniczna)

DOI https://doi.org/10.31261/PLS.2021.11.01.10

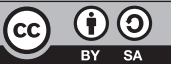

\title{
Prevod kot kulturni in literarni artefakt Primerjava dveh čeških prevodov Prešernove pesmi Slovo od mladosti
}

\author{
Translation As a Cultural and Literary Artefact \\ Comparison of Two Czech Translations \\ of the Poem Slovo od mladosti \\ (Farewall to the Youth) by France Prešeren
}

\author{
Alenka Jensterle-Doležal \\ iD https://orcid.org/0000-0002-0777-5701 \\ CHARLES UNIVERSITY \\ alenka.dolezalova@ff.cuni.cz \\ Datum prijave: 14.01.2021 | Datum recenzije in sprejema: 29. 03.2021
}

\begin{abstract}
In the paper we analyze and compare two translations of Prešeren's poem Slovo od mladosti (Farewell to youth) as cultural and literary artifacts. We focus on linguistic and stylistic solutions as well as decisions in the context of cultural transfer. First, we research the translation by František L. Čelakovski (1799-1852), published in 1832 in the newspaper Časopis českého Museum from the period of romanticism, and second, the translation of the same Prešeren's poem by Josef Hiršal (1920-2003), a famous poet of experimental poetry and a well-known Czech translator of his time, published in the book Mưj sen šel po hladině (My dream faded on the water surface, 1978). We emphasize on Hiršal's translation from the period of the Czech experimental poetry from the sixtieth and seventieth.
\end{abstract}

KEYWORDS | Czech translation of Prešeren's poetry, poems by France Prešeren, F. L. Čelakovský, Josef Hiršal, translating in the Czech culture, Slovene literature in Czech culture 
Prevodi kanoniziranih avtorjev ene kulture v drugo so pomembni mejniki v medkulturnih stikih. Razkrivajo razvoj prevajalskih strategij kot tudi stopnjo prevajalske kulture $\mathrm{v}$ določeni družbi, v primeru poezije kažejo tudi na vprašanje razvoja pesniškega jezika $v$ literarni skupnosti. Vprašanje recepcije in dometa prevoda $\mathrm{v}$ bralski skupnosti je spet pomembno vprašanje $\mathrm{v}$ stiku med dvema kulturama.

Poezija kanoniziranega pesnika Franceta Prešerna ima posebno mesto v slovenski književnosti. Vse od druge polovice 19. stoletja, ko se je začela mitologizacija Prešernove pesniške osebnosti kot tudi kanonizacija njegovega dela, so njegovo poezijo pogosto prevajali tudi v druge književnosti. Prevajanja so se lotevali prevajalci v različnih obdobjih, kar kaže na dejstvo, kako posebno mesto imajo prevodi kanoniziranih literarnih del v sistemu literarnega komuniciranja med različnimi književnostmi. Medliterarni odnosi med Češko in Slovenijo imajo dolgo tradicijo, ${ }^{1}$ Prešernovi prevodi v tem smislu pomenijo mejnik v češko-slovenskih literarnih odnosih. ${ }^{2}$

V prispevku bom analizirala dva prevoda Prešernove pesmi Slovo od mladosti kot kulturna in literarna artefakta in pri analizi drugega - modernističnega prevoda tudi ugotavljala, kako se izraža modernizem in modernistični prevajalčev odnos do jezika in nasploh do gradiva v prevajalski strategiji. Sodobni prevod $\mathrm{z}$ vsemi jezikovnimi in literarnimi dejstvi bom primerjala $\mathrm{z}$ veliko starejšim prevodom $v$ isti kulturi. V žarišču našega raziskovanja bosta dva prevoda pesmi Slovo od mladosti, s katero je komaj devetindvajsetletni France Prešeren leta 1829 začel romantično smer v svoji poeziji. ${ }^{3}$

Ukvarjala se bom s prevodom, ki ga je leta 1832 v časopisu Časopis českého Museum izdal František Ladislav Čelakovský (1799-1852), romantični ustvarjalec in eden od začetnikov umetniškega prevajanja v češki romantiki.

V ospredju mojega zanimanja bo prevod iste Prešernove pesmi Josefa Hiršala (1920 - 2003), ki je bil izdan skoraj sto petdeset let kasneje v knjigi Prešernovih pesmi Můj sen šel po hladině, 1978.

1 Glej tudi B. Urbančič, 1995: Česko-slovinské kulturní styky. Praha, Euroslavica.

2 Glej bazo Prešernovih prevodov. Dostopno iz http://jakrs.si/baza_prevodov/?no_ca che $=1 \&$ tx_jakprevodi_pi1\%5BsearchAvtor\%5D $=231 \&$ cHash $=511456 \mathrm{e} 51 \mathrm{f} 2 \mathrm{e} 442$ 2998fba2fb7459d4a [dostop: 8. 12. 2020].

3 Elegija Slovo od Mladosti je izšla leta 1830 v Kranjski čbelici (v 1. zvezku). To izdajo je tudi imel v roki F. L. Čelakovský. 


\section{I.}

Tradicija češko-slovenskega kulturnega in literarnega sodelovanja sega že $\mathrm{v}$ 16. stoletje, $\mathrm{v}$ romantizmu pa so se stiki med češkimi in slovenskimi intelektualci, jezikoslovci in pisatelji še posebno okrepili. Od revolucije in pomladi narodov leta 1848 se je začela živahna prevajalska dejavnost med obema narodoma, ki se je posebno razmahnila na prelomu stoletja. ${ }^{4}$ Posebno poglavje v 19. stoletju pomenijo stiki med češkimi in slovenskimi intelektualci na koncu 18. in na začetku 19. stoletja, tj. v času razsvetljenskega navdušenja in romantičnega zanosa (na primer med jezikoslovcema: J. Dobrovskim in J. Kopitarjem), v prvem obdobju vzpostavljanja intelektualne mreže povezav, ko so se osnovali temelji za poznejše bogate medsebojne stike. ${ }^{5}$ Intenzivni češko-slovenski literarni stiki v okviru vzhajajoče ideje slovanske vzajemnosti se začenjajo leta 1832 s prvim prevodom štirih Prešernovih pesmi Františka Ladislava Čelakovskega, objavljenih v članku Krajinská literatura v Časopisu českého Museum. ${ }^{6}$ Časopis je bil v redakciji Palackega osrednji organ narodnega prebujanja in je dokazoval enakopravnost češke kulture z že uveljavljenimi narodi drugod po Evropi. Eden glavnih čeških romantikov in prvi Čeh, ki se je »sistematično ukvarjal s spremljanjem razvoja slovenske književnost " ${ }^{7}$ F. L. Čelakovský je v Muzejnem časopisu označil pomen Kranjske čbelice in prevedel štiri Prešernove pesmi: Slovo od mladosti, Hčere svet, Soldaško ter soneta Tak kakor hrepeni oko čolnarja in satirično

4 Petr Mainuš je intenzivne češko-slovenske literarne stike zaradi preglednosti razdelil na šest obdobij: 1. obdobje (1882-1918), 2. obdobje med vojnama (1918-1940), 3. obdobje po drugi svetovni vojni (1946-1948), 4. pasivno obdobje (1949-1956), 5. obdobje popuščanja medsebojnih odnosov (1957-1989) in 6. obdobje od let 1990/1991 dalje. (P. Mainuš, 2005: Bibliografie knižních překladů slovinské literatury do češtiny. Ljubljana, Centrum pro slovinskou literaturu).

5 Glej tudi A. Kozár, 2011: Překlady ze slovinské literatury posledních dvaceti let $v$ českém kulturním kontextu. V: Vzájemným pohledem - V očeh drugega. A. JensterleDoležal, ur., s. 189-198. Praha, NK in M. Przybylski, 2011: Slovinští autoři v českém prostředí. Překlady ze slovinské literatury po roce 1989: stav, proměna a neuralgické body. V: Vzájemným pohledem - V očeh drugega. A. Jensterle-Doležal, ur., s. 229-239. Praha, NK.

6 F. L. Čelakovský, 1832: Krajinská literatura, Časopis českého Museum, 1. 6. Praha, št. 4, s. $443-454$.

7 J. Vinkler, 2006: Posnemovalci, zavezniki in tekmeci. Češko-slovenski in slovensko-češki kulturni stiki v 19. stoletju. Koper, Založba Annales, s. 216-218.

8 Marko Juvan je v tem kontekstu opozoril, da čeprav kritika Čelakovskega izraža simpatije do Slovencev, so v njej kljub vsemu opazna tudi stroga estetska merila in pogled opazovalca iz kulturno bolj razvite metropole, ki je hotela postati center slovanstva. (M. Juvan, 2014: Kritika a preklad jako prostor pro meziliterárnosti: Čop, Čelakovský a Prešeren. V: Slavica litteraria, 1. 17, št. 1. V Brně, Masarykova univerzita, Sborník prací Filozofické fakulty brněnské univerzity, s. 176). 
pesem $O$ kaši ${ }^{9}$ Prvi v češki kulturi je pravilno ocenil razpon Prešernove genialne poetike v času, ko njegove poezije ni priznavalo niti širše slovensko bralstvo doma. Označil ga je kot pesnika, čigar izjemno delo dajejo Kranjski čbelici posebno vrednost in okras: „wýtečné práce zwláštnj cenu a okrasu kragiské Wčelce dáwagj. “10

Tudi Čelakovský je bil izvrsten pesnik, ki je pisal tako lirične pesmi kot tudi umetne epske pesmi po vzoru ljudskega slovstva (pred Prešernovim prevodom je izdal Ohlas písní ruských, Odmev ruskih pesmi, 1829, večino ostalih pesniških zbirk pa je izdal kasneje). Iz slovenščine je prevajal brez posebnega znanja slovenskega jezika. ${ }^{11}$ Prevodi so bili tudi začetek osebne korespondence med pesnikoma, ki se je začela 1833 in je trajala osem let. Pod vplivom Čelakovskega so začeli Prešernove pesmi izdajati v mednarodnih zbornikih slovanske poezije poleg Mickiewicza in Puškina. ${ }^{12}$

Odločitev Čelakovskega za prevod pesmi Slovo od mladosti (K mladosti) je izredno pomembna za uveljavitev Prešerna v češkem okolju. V prevodu občudujemo jezikovno spretnost in zmožnost izbire besed, pa tudi ohranitev pomenskega jedra sporočila. Prešernovo lirsko izpoved je Jože Pogačnik označil kot pesem, v kateri Prešeren svoje razklanosti ne more več premagati z metafizičnim vključevanjem v višjo enotnost in osmišljenost, „v kateri nastane med pesnikovim idealom in resničnostjo pravi romantični prepad. « ${ }^{13} \mathrm{~S}$ tem prevodom je Čelakovský tudi v češki kulturi potrdil Prešerna kot tipičnega romantika, tragično razpetega $\mathrm{v}$ eksistencialni naravnanosti med realnostjo in ideali, med kritiko vsakdanjosti ter družbene realnosti in spomini na preteklost in mladost. V pesmi najdemo tudi pomembne medbesedilne navezave (na Byrona in Schillerja in celo Danteja), vanjo so tudi vtkane biblične in starogrške aluzije, ki so lahko oteževale prevod.

Elegična pesem Slovo od mladosti ima zelo zapleteno arhitekturno kompozicijo in skrbno metrično zgradbo, ki se povezuje s pomensko strukturo pesmi: pesem ima 5 kitic, sestavljenih iz osmih verzov (stanca ali oktava), vsak verz vsebuje osem jambskih enajstercev s prestopno rimo in $\mathrm{v}$ zadnjih dveh verzih z zaporedno (ababab - cc). Dano arhitektonsko zgradbo je Čelakovský

9 Čelakovský je kasneje prevedel in izdal v taistem časopisu še nekaj Prešernovih pesmi: Nápisy - 1835, O epigramách, K mladosti, Sonett, Wojenská leta 1847 in novo izdajo K mladosti in Vojenske leta 1852.

10 F. L. Čelakovský, 1832: Krajinská literatura, Časopis českého Museum 6. Praha, 1. 4, s. 445.

11 S slovenščino se je Čelakovský lahko srečal med študijem v Linzu, kjer se je srečeval s slovenskimi koroškimi študenti.

12 O. Berkopec, 1964: France Prešeren v češki literaturi. Ljubljana, Društvo bibliotekarjev Slovenije, s. 19.

13 J. Pogačnik, 1998: Slovenska književnost I. Ljubljana, DZS, s. 253. 
poizkušal poustvariti v okviru ritma in stila češkega jezika, podobno kot je hotel obliko uskladiti tudi s pomenskimi plastmi originala, saj je skrbno sledil posameznim pomenom verza in kitice in tudi pomenskemu toku v izpovedi, "gostoti in lahkosti ter tudi melodičnemu ritmu izpovedi«. Med prvimi šestimi in zadnjima dvema verzoma je pomenska zareza, ki se izraža tudi s spremenjeno rimo in tudi to je prevajalec poizkusil ohraniti. Današnji bralec, ki pri branju uspe razvozlati staro češko pisavo in pravopis, se sreča $\mathrm{z}$ izbiro besed, ki neposredno evocirajo tedanjo zgodovinsko realnost: vsekakor je prevajalec $\mathrm{z}$ izbiro jezikovnih in stilističnih možnosti v prevodu ustvaril primerno kuliso romantične dobe, kjer se »ctnost a svědomí« (Čelakovskega izbor besed, prevod AJD: »moralna neoporečnost in vest«) ne cenita dovolj. Jonatan Vinkler tako ovrednoti prevod Čelakovskega Slovesa od mladosti in sploh celotnega izbora: »Mogoče je torej reči, da je Čelakovský za izrazna sredstva, ki jih je Prešeren uporabil v izvirniku, našel ustrezne odgovore tudi v češčini, in to tako, da je upošteval njihovo funkcijo v pesniški zgradbi, njihovo sporočilno, pomenotvorno vrednost in stilotvorno zaznamovanost. $"{ }^{14} \mathrm{Ni}$ naključje, da je Čelakovský prevod Slovesa od mladosti izdal še dvakrat.

Čelkovskega prevod pesmi Slovo od mladosti je korekten in dosleden: pomensko dovršen v strogi arhitekturi petdelnega besedila in v upoštevanju metričnih zahtev in rimanja. V izbiri besed tudi zaznamo tipični besednjak češke romantične dobe. Čelakovský je bil drugačen romantični pesnik kot Prešeren, saj v sebi ni nosil takšne globine tragične razpetosti, kot jo najdemo tudi pri nekaterih evropskih romantičnih ustvarjalcih, na primer pri Byronu ali Schillerju, tako da se v prevodu nekoliko izgubi bolečina osebne elegične izpovedi iz Prešernovega originala.

Tudi kasneje so na Češkem večkrat prevajali Prešernove pesmi. Mladi entuziast Josef Penížek je leta 1882 izdal Prešernove prevode v knjižni obliki pri provincialni založbi v Jičínu. Naredil jih je brez večjega znanja slovenskega jezika in tudi brez predhodnih prevajalskih izkušenj, tako da ta prevod nima večje prevajalske vrednosti. ${ }^{15} \mathrm{~V}$ Narodni in univerzitetni knjižnici v Ljubljani se nahaja rokopis prevoda celotnih Prešernovih pesmi od neznanega prevajalca: Básně páně doktora Františka Prešerna iz 1860 (hranijo se v rokopisnem oddelku NUK-a, signatura Ms. 510). ${ }^{16}$ Šele Hiršalov prevod v sedemdesetih letih 20. stoletja pomeni res umetniški prevod Prešernove poezije in vrnitev

14 J. Vinkler, 2006: Posnemovalci, zavezniki in tekmeci ..., s. 251.

15 Po Penížku sta ga časopisno prevajala tudi F. Doucha in J. Borecký (A. Kozár, 2003: Aktualizace jazykové normy v překladu (France Prešeren v českém překladu Josefa Hiršala), s. 1. Dostopno na internetu: https://digilib.phil.muni.cz/bitstream/handle/11222. digilib/123253/SpisyFF_338-2002-1_25.pdf?sequence=1 [dostop: 8. 12. 2020]).

16 J. Vinkler, 2006: Posnemovalci, zavezniki in tekmeci ..., s. 251. 
k »rekonstrukciji Prešernovega duha«. Pomembno je tudi politično-kulturno razumevanje njegovega prevoda v kontekstu povojnega dogajanja in dogajanja po letu 1968. Interpretiramo ga lahko kot pogumen poskus ohraniti medkulturno sodelovanje in izmenjavo med dvema malima kulturama v prostoru Srednje Evrope. V obdobju češkega totalitarnega režima je kljub prepovedim in pritiskom Josef Hiršal uspel (pod drugim imenom) prevesti najpomembnejše slovenske pesnike in tudi vrhunske Prešernove pesmi v češki jezik.

\section{II.}

Razcvet sodelovanja med češkim in slovenskim narodom je po drugi svetovni vojni nasilno prekinil razkol med Jugoslavijo in ZSSR. V letih 1949-1953 iz političnih razlogov ni izšel noben prevod slovenske (in tudi srbske in hrvaške) literature. Odnosi so se tudi v kulturi počasi spletali, šele v šestdesetih letih je s praško pomladjo nastopila renesansa medsebojnih literarnih odnosov. Spet so se prevajali klasiki kot Ivan Cankar, pa tudi Srečko Kosovel, France Bevk ali Oton Župančič. S sovjetsko okupacijo in totalitarnim režimom po letu 1968 so bili češko-slovenski stiki do leta 1989 spet oteženi in pod ideološkim pritiskom.

Josef Hiršal (1920-2003) je v literaturo vstopil na začetku druge svetovne vojne, $\mathrm{v}$ petdesetih in šestdesetih letih se je uspešno posvečal eksperimentalni poeziji. ${ }^{17}$ Češko avantgardno sceno je povezal z mednarodno, evropsko eksperimentalno poezijo je tudi prevajal. Zavest o novih smereh konceptualne in vizualne poezije je $\mathrm{v}$ češki literarni skupnosti $\mathrm{v}$ šestdesetih letih $-\mathrm{v}$ času sprostitve in večje svobode — širil s predavanji in razstavami. Prevajal je tudi študije in filozofske članke o eksperimentalni in vizualni poeziji - na primer študije nemškega filozofa Maxa Benseja. Poleg Jiř́ija Kolářa in Ladislava Novaka je spadal med ključne osebnosti avantgardne smeri. Večino svojega dela je načrtoval skupaj s partnerico Bohumilo Grögerovo, s katero sta izdala tudi več antologij eksperimentalne poezije: Experimentální poezie (1967), Slovo, písmo, akce, hlas (Beseda, pisava, akcija, glas, 1967), Vrh kostek (Vrh kock,1993). Njegova najbolj znana eksperimentalna zbirka se imenuje JOB BOJ. Izdal jo je $1968-$ spet skupaj z Bohumilo Grögerovo.

17 Julija 2020 so v češki kulturi praznovali sto let Hiršalovega rojstva. Že v času češkega totalitarnega režima je bil Hiršal v Evropi deležen mednarodnih priznanj. Skupaj z Bohumilo Grögerovo je leta 1986 dobil nagrado Toma Stopparda. Leta 1988 mu je bila podeljena nagrada Egona Hostovskega.

\begin{tabular}{l|l} 
PLS.2021.11.01.10 & s. $6 \mathrm{z} 15$
\end{tabular} 
Zgodba njegovega pisateljskega in prevajalskega vzpona in potem zatona in prepovedi objavljanja je tipična zgodba češkega intelektualca v totalitarnem obdobju po letu 1968. Od tega leta je bil v nemilosti pri novem normalizacijskem režimu in je moral izdajati prevode svetovne klasike pod drugimi imeni sodelavcev in prijateljev. Tudi večino svojih pesniških zbirk je izdal v eksilu. Pod tujimi imeni so izhajali Hiršalovi prevodi do leta $1990 .^{18}$

Hiršalov prevod Prešernovih pesmi leta 1978 pomeni izjemen dogodek za prevajanje slovenske poezije na Češkem. Prevod je opravil modernistični pesnik in izkušeni prevajalec, ki je pred tem sodeloval tudi pri prevajanju Otona Župančiča (1964), ${ }^{19}$ že leta 1972 pa je prevedel pesmi Edvarda Kocbeka. ${ }^{20}$ Hiršal je bil v tem obdobju uveljavljen pesnik, ki je do prevoda Prešernovih pesmi izdal že osem pesniških zbirk. Prevajal je iz šestnajstih jezikov, veliko je prevajal predvsem nemško poezijo, prevajal pa je tudi iz kitajščine, perzijščine, a tudi iz romunščine in srbščine. ${ }^{21}$

Zaradi totalitarnega režima v sedemdesetih letih je prevod izbora Prešernovih pesmi s tipičnim romantičnim naslovom Mi̊j sen šel po hladině (Moj sen se je izgubil po gladini, 111 s.) lahko izšel samo pod imenom brnskega profesorja Viktorja Kudělka, ${ }^{22}$ ki je pomagal sicer izkušenemu prevajalcu s slovenskim jezikom, saj predpostavljamo, da Josef Hiršal ni znal slovensko. Izbor je bil tematski, prevedel je večino Prešernove ljubezenske in refleksivne lirike, Sonetni venec in samo del pesnitve Krst pri Savici. S tem je delno omejil celostno podobo Prešernove poezije; izbor je lahko bila tudi sugestija založbe ali urednika.

Aleš Kozár je leta 2003 opozoril na načrtno Hiršalovo strategijo pri prevajanju Prešernovih pesmi: na »aktualizacijo jezikovne podzavesti recipienta «. Izpostavil je prevajalčevo namerno arhaizacijo poetičnega jezika in to ne samo pri izbiri besed, ampak tudi v sintaksi, stilističnih pesniških figurah in besednem redu. Hiršal je $\mathrm{z}$ izrednim enciklopedičnim spominom jezikovno normo

18 L. Marková, 2011: Josef Hiršal - monografická studie. Diplomová práce. Praha, Karlová univerzita, s. 54. Dostopno na internetu: is.cuni.cz > webapps > zzp > detail [dostop: 8. 12. 2020].

19 Hiršal je pri prevajanju iz jezikov, ki jih ni obvladal, vedno sodeloval s strokovnjaki za določen jezik. Pri prevajanju Župančičevih pesmi je sodeloval s slavistom Otonom Berkopcem. Izbor pesmi je izšel pod naslovom Úsvity a bouře (Zarje in nevihte). Ostale prevode so naredili pesniki: J. Hora, P. Kopta, L. Kubišta, J. Urbánková in V. Závada.

20 E. Kocbek, 1972: Kruté kruhy (Kruti krogi, izbor iz zbirke Groza / Poročilo). J. Hiršal, prev. Praha, Odeon.

21 Glej http://databaze.obecprekladatelu.cz/databaze/H/HirsalJosef.htm [dostop: 8. 12. 2020].

22 Viktor Kudělka je k pesmim napisal obširen strokovni uvod, v katerem je razložil tako kulturni kontekst slovenske romantike kot tudi poudaril glavne konstante Prešernove poezije. 
prevoda prilagajal normi jezika 19. stoletja in pri tem namerno uporabljal tudi tipične machovske stileme in oksimorone. ${ }^{23} \mathrm{~V}$ smislu aktualizacije lahko razumemo njegov modernistični in eksperimentalni pristop do jezikovnega gradiva. Tovrstno poustvarjanje zgodovinske norme pa ima korenine tudi v njegovem ustvarjanju. V pesniški zbirki Parkář (Hrenovkar, 1997), ki jo je Hiršal pisal v sedemdesetih letih po fazi eksperimentalne poezije, je začel uporabljati formo modernega pastiša, ki ga je razumel kot posnemanje ali parafrazo določenega stila kanoniziranih čeških avtorjev tudi iz obdobja romantike: K. J. Erbena, K. H. Máche, F. L. Čelakovskega in drugih ... in se je pri tem prav pri imitacijah dosežkov češke romantične poezije učil in pilil "psevdoromantični slog" izražanja in eksperimentiral s preteklo jezikovno normo. ${ }^{24}$

$\mathrm{V}$ enem od najbolj izrazitih prevodov Prešernovih pesmi Loučení s mladím (Slovo od mladosti) je Hiršal spretno uporabil prefinjene prevajalske sposobnosti kot tudi vključil igriv odnos do jezika kot nenapisan moto modernističnega pesnika in prevajalca. Tu ta njegov prevod lahko razumemo kot formo pastiša, poustvarjanja določene romantične norme, s katero se je lahko inspiriral pri čeških romantikih. Tudi tu je okrepil jambski ritem s tem, da je poudaril trozložne začetke verzov in upadajoči konec verza. ${ }^{25}$ Marie Langerová v članku o češki eksperimentalni poeziji poudarja, da je bila to "poezija nove zavesti« in da je bil pri avtorjih te poezije poudarek na jeziku: jezik so razumeli kot materialno in vizualno kvaliteto, ki nosi predvsem estetsko informacijo. Pesniki eksperimentalne poezije so tako začeli z destrukcijo konvencionalnih jezikovnih zgradb, ki so jih razumeli kot nefunkcionalne: s tem da se "usmerjajo v notranjo energijo pisave«. ${ }^{26}$ (Langerová 1998: 308) Za prevajalca Hiršala, ki je bil hkrati tudi znan avtor eksperimentalnih pesmi, je bila tudi $\mathrm{v}$ prevodu pomembna vsaka beseda in njena razporeditev $\mathrm{v}$ prostoru, kar pa je še posebno veljalo za tako kompleksno pesem Slovo od mladosti, ki še danes v bralčevi zavesti zares zaživi na metaforični, simbolni ravnini. Ne glede na eksperimentalne izkušnje, ki jih je gotovo imel veliko, pa je pesnik

23 A. Kozár, 2003: Aktualizace jazykové normy v překladu ..., s. 2.

24 Parafraze so $\mathrm{v}$ tej zbirki namerne in nosijo tudi potujevalni efekt. Poigravanje $\mathrm{z}$ jezikom in tudi s smislom se vedno zaključi s humornim podtonom: $\mathrm{v}$ vseh pastiših se pojavi motiv hrenovk, prodajalcev hrenovk in klobas. Hiršal je parafraziral Máchovo pesnitev Maj v melanholičnem in liričnem tonu, prav ta pesnitev pa mu je lahko bila vir inspiracij tudi za Prešernovo poezijo tako v jezikovni izbiri kot tudi z oblikovanjem atmosfere in tragičnosti, ki se ponekod »zamenja in nadgradi«s humorno perspektivo ... Hiršal je moderne pastiše posvetil Jiř́iju Kolařu, vodilni osebnosti češke slikarske scene, ki se je proslavil predvsem s kolaži.

25 A. Kozar, 2003: Aktualizace jazykové normy v překladu ..., s. 2.

26 M. Langerová, 1998: Experimentální poezie šedesátých let. Česká literatura, 1. 46, št. 3. Praha, s. 308. 
in prevajalec Hiršal moral upoštevati Prešernovo klasično formo romantične izpovedi, ki jo najdemo $\mathrm{v}$ tej elegiji, še posebno, ker je to kanonizirano besedilo v slovenski literaturi. V procesu prevajanja je lahko »doživljal konflikte v svojem modernističnem prepričanju«; v tem smislu lahko razmišljamo o njegovi samodisciplini pri upoštevanju pesniških norm 19. stoletja. Motivi, primere in podobe odražajo metafizično prepričanje in emocionalno stanje lirskega subjekta. Prevajalec je moral previdno izbirati in se odločati posebno $\mathrm{v}$ kombinaciji frazemov in genitivnih metafor, kjer se mešajo konkretni in abstraktni izrazi. Josef Hiršal je poizkušal obdržati strogi ritem in rimanje iz originala tudi v prevodu. Pesem v prevodu je zelo melodična, tudi zaradi rim in metričnih zakonitosti je moral prevajalec še bolj iskati v slovarju možnosti in to ga je morda delno omejevalo v dobesednem prevodu posebno abstraktnih fragmentov.

Posebno uspel je prevod četrte kitice s štirimi metaforičnimi slikami, ki zaživijo $\mathrm{z}$ vso simbolično ostrino in podobo pesnikove težke eksistencialne situacije.

Te videt, grje videti napake, je srcu rane vsekalo krvave; mladosti jasnost vendar misli také si kmalu iz srca spodi in glave, gradove svetle zida si v oblake, zelene trate stavi si v puščave, povsod vesele lučice prižiga ji up goljf'ivi, k njem iz stisk ji miga. ${ }^{27}$

Z poznání tech a horších nespavostí Z poznání tech a horších nespavostí jsou jizvy, jichž se srdce sotva zbaví. Jen světlo mládí ještě se jich zhostí, když vyhání je ze srdce a hlavy, v oblacích vzdušné zámky závratností, na pouštích lány zelené si staví, vesele jiskry ve tmě rozškrtávás nadějí bludnou, zvoucí do modravá. ${ }^{28}$

Prevajalec verodostojno sledi loku pomenov in skritim pomenskim težiščem $\mathrm{v}$ verzih in kiticah, pomenski poudarki ustvarjajo prepričljive slike in nenavadne obrate. Samo včasih v strukturi žrtvuje določene pomene, da bi poudaril

27 F. Prešeren, 1960: Pesmi in pisma II. A. Slodnjak, ur. Ljubljana, s. 48, 49.

28 F. Prešeren, 1978: Loučení s mladím. V. Kudělka, uvod. J. Hiršal, prev. Praha, s. 60, 61. 
spevnost in poseben ritem, na primer v zadnjem verzu pete kitice. Fragment pri bralcu, ki pozna tudi original, že izzveni v originalen zapis („s nadějí bludnou, zvoucí do modravá«, dobeseden prevod: „z blodnim upanjem, ki poziva v modrino «).

Pesem Slovo od mladosti je sklenjena, harmonična celota, v kateri se mešata in v izpovedi prepletata dve znani Prešernovi kategoriji: up in brezup, to prepletanje pa v toku lirske izpovedi dobro evocira tudi Hiršalov prevod.

Samo včasih se pri prevajanju v iskanju celote in pri upoštevanju formalnih zahtev določene povezave in metaforični izrazi iz originala izgubijo. Zaradi celotne strukture je prevajalec moral žrtvovati Prešernovo tako povedno eksistencialno sintagmo »temna zarja«, ki v svoji protislovnosti razkriva pesnikovo razklanost in dvojnost razumevanja mladosti, in jo nadomestiti z izrazom »svetla zemlja«. ${ }^{29}$ Izguba oziroma temeljna sprememba eksistencialne metafore, ki je v elegiji namerno poudarjena na začetku in na koncu pesmi, osiromaši prevod za ključno pomensko jedro, ki tudi tematizira razpetost Prešernove izpovedi med upanjem in brezupom. ${ }^{30}$

\section{III.}

V prispevku sem analizirala Hiršalov prevod Prešernove pesmi Slovo od mladosti v češčino kot kulturni in literarni artefakt in tudi ugotavljala, kako se izraža modernizem v prevajalski strategiji tudi s tem, da sem sodobni prevod primerjala $z$ veliko starejšim prevodom v češki kulturi. Josef Hiršal je v nasprotju s Františkom Ladislavom Čelakovským pristopil k prevajanju Prešernove elegije Slovo od mladosti z izkušnjo modernizma in eksperimentalne poezije, s sodobno jezikovno normo. Kot prevajalec in avtor je dobro poznal aktualno češko jezikovno normo v sedemdesetih letih. V ozadju slutimo njegove izkušnje z metodami konstrukcije in dekonstrukcije v literaturi in poeziji in na splošno drugačen, eksperimentalen pristop do jezika in jezikovnih norm. Jezik tudi v prevodu postane zanj tema sama po sebi, posebna kategorija. Prav Hiršalov prevod razkriva, da je še posebno pomemben prevajalčev odnos do modernega

29 Čelakovský je v tem primeru iz tedanjega besednjaka še ustvaril pomensko podobno sintagmo glede na original: »tmává zoře«. (Beseda zoře je v Slovarju češkega jezika iz leta 1971 označena kot že zastarela beseda (Slovník spisovného jazyka českého IV, $V-Z ̌$. Praha, Nakladatelství Československé Akademie Věd, 1971).

30 Čelakovský je za ključno izbral sintagmo: „temna zoř“, ki je dobeseden prevod iz slovenščine v romantično češčino: „Po temné zoři twé- s bohem, mladosti“ (F. L. Čelakovský 1832: Krajinská literatura ..., s. 446). Zoře je danes že zastarela beseda. 
jezika, saj je jezik nosilec pomembnih konotacij, stilističnih, pragmatičnih in tudi izvenjezikovnih vrednosti literarnozgodovinskega konteksta. Osredotočila sem se na nekatere jezikovne in stilistične rešitve in tudi odločitve $\mathrm{v}$ okviru kulturnega transfera, odvisnega tudi od konteksta.

Josef Hiršal je kot pesnik, ki je za seboj imel izkušnje konkretne in vizualne poezije ter izkušnje poigravanja $\mathrm{z}$ jezikom - in tudi eksperimentiranja z njegovo vizualno stranjo, imel originalen in ustvarjalen odnos do obeh jezikovnih norm: do modernizma in tudi do romantične tradicionalne norme $\mathrm{v}$ poeziji. $\mathrm{V}$ tem obdobju se je nahajal $\mathrm{v}$ obdobju posnemanja in poigravanja s češko romantično jezikovno normo, ki jo je delno uporabil tudi pri prevodu pesmi romantika Prešerna.

Slovenci morajo v prihodnosti še posebno oceniti prevajalca Hiršala kot izkušenega stilista, ki je v težkem obdobju češko-slovenskih odnosov občutljivo in kvalitetno prevedel kar dva ključna pesnika iz slovenske literature: E. Kocbeka in F. Prešerna. Njegovo prevajalsko vlogo v okviru slovensko-čeških odnosov je treba še posebno poudarjati, saj je njegovo ime pri teh prevodih uradno izbrisano in zanj vedo le tisti, ki se strokovno ukvarjajo s prevajanjem iz slovenske literature $\mathrm{v}$ češki jezik.

Znani češki germanist in kafkolog Eduard Goldstücker je leta 1958 v reviji Literární noviny tako ocenil Hiršalov prevod nemškega pesnika Morgenster$\mathrm{na}^{31}$ in njegovih pesmi Šibeničné písní (prav ta prevod je Hiršala proslavil kot vrhunskega prevajalca $v$ češki javnosti): »Převést takového básnění $z$ jedné řeči do druhé je úkol zdánlivě nemožný. S pouhým překládáním, tj. řazením významových ekvivalentů jednotlivých slov zde daleko nedojdeš. Každý autorův nápad je nutno doslova přebásnit $\mathrm{v}$ duchu rodné řeči, ponořit se do jejích hlubin a s velkou trpělivostí hledat kongeniálně vtipný účin v jejich nepřeberných fondech. Josefu Hiršalovi se to podařilo v míře hodné obdivu. Jeho dílo lásky a vytrvalosti je záslužný čin ve službách jazyka i ve službách čtenářské obce, jíž přináší chvíli blaživého smíchu. (Prevod AJD: »Prevesti tovrstno pesnjenje iz enega jezika $v$ drugega je na videz nemogoča naloga. S samim prevajanjem, to je z razvrščanjem pomenskih ekvivalentov za posamezne besede, tukaj daleč ne prideš. Vsako avtorjevo idejo je nujno dobesedno prepesniti v duhu maternega jezika, potopiti se $\mathrm{v}$ njegove globine in $\mathrm{z}$ veliko potrpežljivostjo iskati kongenialno primerna jezikovna sredstva v njegovih neskončnih fondih. Josefu Hiršalu je to uspelo v meri, ki si zasluži naše občudovanje. Njegovo delo ljubezni in

31 Christian Otto Josef Wolfgang Morgenstern (1871-1914) je bil začetnik nemške poezije nonsensa. Josef Hiršal je že leta 1958 najprej prevedel njegovo pesniško zbirko Galgenlieder (1905, naslov preveden v češčino kot Šibeničné písní, Visliške pesmi), ki je sestavljena iz lirskih pesniških poskusov (igrivih besednih obratov), v katerih prevajalec preizkuša jezik in njegove možnosti. 
vztrajnosti je hvalevredno dejanje v službah jezika in v službah bralske skupnosti, ki prinaša trenutek blaženega smeha. «) ${ }^{32}$

Jiří Levy je še leta 1967 v uvodu v sintetično monografijo o zgodovini prevajanja na Češkem poudaril, da je razvoj prevajalske estetike del celotnega razvoja estetskih nazorov in ta spet del razvoja češke literature in kulture. ${ }^{33}$ Uspehi v prevajanju poezije na Češkem od šestdesetih let 20. stoletja so bili tako številni tudi zaradi razvoja in razmaha čeških pesniških form v drugem valu češkega modernizma. Tudi Roman Jakobson je v svoji refleksiji o prevajanju poudaril prav stanje danega pesniškega jezika kot pomembno dejstvo pri prevajanju, saj je bil prepričan, da se umetniško najbolj približamo originalu tedaj, kadar je za odmev tujejezičnega dela izbrana forma, ki v okviru oblik danega pesniškega jezika funkcionalno, ne zares, odgovarja obliki originala. ${ }^{34}$ Hiršalov prevod Prešernove pesmi Slovo od mladosti, podobno kot ostali prevodi v prevedeni knjigi, odraža tako razvoj čeških pesniških oblik v sedemdesetih letih kot tudi njegov osebni pesniški razvoj, v katerem je prešel iz obdobja eksperimentalne faze $\mathrm{v}$ fazo pastišev in posnemanja. Prevajanje tako v tem primeru ni bil samo jezikovni dogodek, ampak tudi medliterarni in kulturni.

Prispevek naj končamo s parafrazo misli Marka Juvana, da se omenjena medbesedilna zrcaljenja in metatekstualno okvirjanje med slovenskim in češkim literarnim poljem uvrščajo v evropski proces oblikovanja svetovne literature, narodnih literatur in medliterarnih družb. ${ }^{35}$ Prevodi Josefa Hiršala so v tem smislu vzorčni primer, saj je prav on kot ustvarjalec medknjiževnih in mednarodnih dogodkov in literarnih stikov v srednjeevropskem prostoru v enem od najtežjih obdobij literarnega in kulturnega transferja med dvema narodoma $s$ češkim prevodom Prešernovega teksta oblikoval enega od kvalitetno najbolj zahtevnih prevodov.

32 Glej Literární noviny, 1. 41, 1958, 11. 10., s. 4, prevzeto iz L. Marková, 2011: Josef Hiršal - monografická studie. Diplomová práce. Praha, Karlová univerzita, s. 33. Dostopno na internetu: is.cuni.cz > webapps > zzp > detail [dostop: 8. 12. 2020].

33 J. Levy, 1963: Umění překladu I. Praha, Ivo Železný, s. 6.

34 R. Jakobson, 1995: O překladu veršů. V: Poetická funkce. Praha, Nakladatelství H H, s. $145-147$.

35 M. Juvan, 2014: Kritika a překlad jako prostor pro meziliterárnosti ..., s. 179. 


\section{Literatura}

Berkopec O., 1964: France Prešeren v češki literaturi. Ljubljana, Društvo bibliotekarjev Slovenije.

Jakobson R., 1995: O překladu veršů. V: Poetická funkce. Praha, Nakladatelství H H, s. 145-147.

Juvan M., 2014: Kritika a přkeklad jako prostor pro meziliterárnosti: Čop, Čelakovský a Prešeren. V: Slavica litteraria, 1. 17, št. 1. V Brně, Masarykova univerzita, Sborník prací Filozofické fakulty brněnské univerzity, s. 175-185.

Kozár A., 2003: Aktualizace jazykové normy v překladu (France Prešeren v českém překladu Josefa Hiršala). Dostopno na internetu: https://digilib.phil.muni. cz/bitstream/handle/11222.digilib/123253/SpisyFF_338-2002-1_25.pdf? sequence $=1$ [dostop: 8.12 .2020 ].

Kozár A., 2011: Překlady ze slovinské literatury posledních dvaceti let v českém kulturním kontextu. V: Vzájemným pohledem - Vočeh drugega. A. JensterleDoležal, ur. Praha, NK, s. 189-198.

Langeová M., 1998: Experimentální poezie šedesátých let. Česká literatura, 1. 46, št. 3. Praha, s. 308-319.

Levy J., 1963: Umění překladu I. Praha, Ivo Železný.

Mainuš P., 2005: Bibliografie knižních překladi̊ slovinské literatury do češtiny. Ljubljana, Centrum pro slovinskou literaturu.

Marková L., 2011: Josef Hiršal — monografická studie. Diplomová práce. Praha, Karlová univerzita. Dostopno na internetu: is.cuni.cz > webapps > zzp > detail [dostop: 8. 12. 2020].

Pogačnik J., 1998: Slovenska književnost I. Ljubljana, DZS.

Prešeren F., 1960: Pesmi in pisma II. A. Slodnjak, ur. Ljubljana, Mladinska knjiga. Przybylski M., 2011: Slovinští autoři v českém prostředí. Překlady ze slovinské literatury po roce 1989: stav, proměna a neuralgické body. V: Vzájemným pohledem - V očeh drugega. A. Jensterle-Doležal, ur. Praha, NK, s. 229-239.

Urbančič B., 1995: Česko-slovinské kulturní styky. Praha, Euroslavica.

Vinkler J., 2006: Posnemovalci, zavezniki in tekmeci. Češko-slovenski in slovensko -češki kulturni stiki v 19. stoletju. Koper, Založba Annales.

\section{Prevodi}

Čelakovský F. L., 1832: Krajinská literatura, Časopis českého Museum 6. Praha, t. 4, s. $443-454$.

Prešeren F., 1988: Básně Františka Preširna. J. Penížek, prev. V Jičíně, Lad. Sehnal. Prešeren F., 1978: Loučení s mladím, uvod Viktor Kudělka (Živý odkaz mrtvého básníka Živ odmev mrtvega pesnika). J. Hiršal, prev. Praha, Odeon. 
Baza Prešernovih prevodov: http://jakrs.si/baza_prevodov/?no_cache=1\&tx _jakprevodi_pi1\%5Bsearch Avtor\%5D=231\&cHash $=511456 \mathrm{e} 51 \mathrm{f} 2 \mathrm{e}$ 4422998fba2fb7459d4a [dostop: 8. 12. 2020].

\section{Alenka Jensterle-Doležal \\ Prevod kot kulturni in literarni artefakt Primerjava dveh čeških prevodov Prešernove pesmi Slovo od mladosti}

POVZETEK | V prispevku analiziram dva prevoda Prešernove pesmi Slovo od mladosti kot kulturna in literarna artefakta: prevod Františka Ladislava Čelakovskega (1799-1852) iz leta 1832 (izdan v časopisu Časopis českého Muzea) kot tipičen prevod romantičnega ustvarjalca in enega od začetnikov prevajanja umetniških del na Češkem ter prevod taiste Prešernove pesmi Josefa Hiršala (1920-2003), ki je bil izdan v knjigi France Prešeren, Mưj sen šel po hladině, 1978. Pri analizi drugega prevoda ugotavljam, kako se izraža modernizem v prevajalski strategiji. Prevod je primer jezikovne mojstrovine slavnega pesnika eksperimentalne poezije in znanega prevajalca (zaradi političnih razmer se je pod prevod podpisal urednik knjige Viktor Kudělka). V primerjavi me zanimajo tako jezikovne in stilistične rešitve kot tudi kulturološka vprašanja in vprašanje zgodovinskega konteksta. Hiršalov modernistični prevod je izhajal iz razvoja čeških pesniških norm $\mathrm{v}$ šestdesetih in sedemdesetih letih 20. stoletja.

KLJUČNE BESEDE | češki prevodi Prešernove poezije, F. L. Čelakovský, Josef Hiršal, prevajanje $\mathrm{v}$ češčino, slovenska književnost $\mathrm{v}$ češki kulturi

\section{Alenka Jensterle-Doležal \\ Translation As a Cultural and Literary Artefact \\ Comparison of Two Czech Translations of the Poem Slovo od mladosti (Farewall to the Youth) by France Prešeren}

SUMARRY | In the paper we analyze and compare two translations of Prešeren's poem Slovo od mladosti (Farewell to youth) as cultural and literary artifacts. We focus on linguistic and stylistic solutions as well as decisions in the context of cultural transfer, which also depends on the context. We research the translation by František Ladislav Čelakovski (1799-1852) from 1832 (published in the Časopis českého Muzea) and the translation of the same Prešeren poem by Josef Hiršal (1920-2003), published in the book Můj sen šel po hladině (My dream faded on the water surface, 1978). Hiršal's modern translation emerged from a certain development of Czech poetic norms in the 1960s and 1970s and is an example of a linguistic masterpiece by the famous poet of the experimental poetry and a well-known translator (due to political circumstances, the translation was signed by the book's editor Viktor Kudělka).

KEYWORDS | Czech translation of Prešeren's poetry, poems by France Prešeren, F. L. Čelakovský, Josef Hiršal, translating in the Czech culture, Slovene literature in Czech culture 
ALENKA JENSTERLE-DOLEŽAL | doc. dr., je predavateljica za slovensko književnost, slovanske književnosti in literarno teorijo na Katedri za južnoslovanske in balkanistične študije na Filozofski fakulteti Karlove univerze v Češki republiki. Od leta 2002 živi v Pragi. Izhaja iz Slovenije, kjer je leta 1983 diplomirala iz slovenščine, primerjalne književnosti (B) in filozofije (B), leta 2000 je doktorirala iz Mita o Antigoni v južno- in zahodnoslovanskih dramah. Je avtorica šestih monografij in številnih znanstvenih študij. Uredila je pet kolektivnih monografij in zbornikov ter organizirala številna znanstvena srečanja v Pragi. Njene raziskovalne teme so: slovenska moderna, slovenske avtorice, mit v književnosti in slovensko-češki odnosi. Je tudi pisateljica: objavila je pet knjig poezije in dva romana. 